\title{
The Effects of Different Excavation Angle on Intersecting Tunnel Surrounding Rock Stability
}

\author{
Jinkui Li ${ }^{\mathrm{a}}$, Xianke Wei ${ }^{*}$, and Wenjing Liang ${ }^{\mathrm{c}}$ \\ Department of Civil and Architecture Engineering,Dalian University, Dalian 116622, China \\ ajinkee@126.com, b18617561784@163.com, ${ }^{\mathrm{c}}$ liangwenjing999@163.com
}

\begin{abstract}
Various contacting channels and intersecting tunnels often need to be constructed in the tunnel construction process. While in the process of intersecting tunnel construction, the excavation of back tunnel will cause surrounding rock and supporting structure stress adjustment and redistribution. The excavation of two crossing tunnels will cause lots of changes in the rock and supporting structure mechanical characteristics. It has great impact on the intersection of the stress and deformation. The background of this paper is the Dalian subway project and selects excavation angle of $30^{\circ}, 45^{\circ}$ and $90^{\circ}$. In order to obtain the supporting structure stress change and deformation of surrounding rock in the process of main tunnel and intersecting tunnel excavation with different angle, this paper use MIDAS/GTS to carry on the numerical simulation and analysis earth surface settlement, vault, clear convergence variation. Finally it obtains the reasonable angle of intersecting tunnel and to guide the construction of the project smoothly.
\end{abstract}

Keywords-Intersecting tunne; Excavation angle; Numerical simulation; Supporting structure; Deformation of surrounding rock.

\section{INTRODUCTION}

Our Academy of Engineering, Wang Mengshu from the height of "sustainable development", proposed the "era of the 21 st century is the tunnel and underground space development"[1]. In the field of tunnel construction, attracted a growing number of scholars to explore and study. Currently, there are many domestic and foreign scholars have related research on intersecting tunnel [2-8], and gradually accumulated some experience and results, But they mostly concentrated in the form of tunnel section, mechanics, construction methods, construction technology and support systems, etc. They studied relatively few and inadequate in the rationality of the excavated angle and there are many problems to be solved. This paper use MIDAS-GTS finite element numerical simulation to choice the reasonable angle of intersecting tunnel as well as provide reference for similar tunnel projects according to the engineering geological conditions, difficulty in construction and design requirements.

\section{PROJECT SUMMARY}

The interval from promotion road station to Spring Street station adopt excavation method and design scope for mileage, DK11+365.945 DK12+013.350, right line length $647.405 \mathrm{~m}$, left line length $644.039 \mathrm{~m}$. The line of this range layout along north-south of promotion road, via Xiang Zhou Road and through the "second industrial erection engineering company" factory and the "Dalian iceberg Sanyo washing limited company" factory. The distance between lines is $13 \mathrm{~m} \sim 4.6 \mathrm{~m} \sim 12.615 \mathrm{~m}$. In order to ensure the tunnel away from buildings on both sides of road as far as possible, the engineer set up $300 \mathrm{~m}$ and $1000 \mathrm{~m}$ radius curve each side. The distance between lines is from $13.4 \mathrm{~m}$ to $4.6 \mathrm{~m}$. The engineer set a single cross the line and set a $400 \mathrm{~m}$ radius curve after Xiang Zhou Road. Tunnel surface topography fluctuation is bigger. The ground elevation is from $7.79 \mathrm{~m}$ to $10.58 \mathrm{~m}$. Tunnel vault covering the largest is $16.9 \mathrm{~m}$ and the minimum is $13.14 \mathrm{~m}$. The section of the paper selected AK11+908. Artificial accumulation thickness is $4.2 \mathrm{~m}$. Diluvium thickness is $3.5 \mathrm{~m}$ and slate thickness is $34.5 \mathrm{~m}$. Intersecting tunnel layout and tunnel profile as shown:
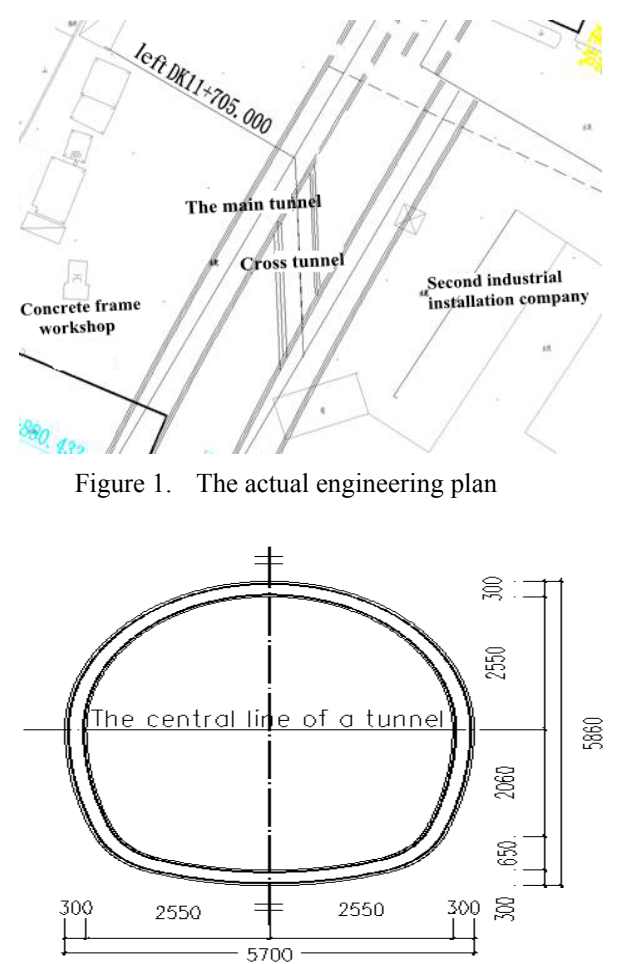

Figure 2. The section size of tunnel

III. PARAmeter Selection AND MOdeling

This project uses shot concrete, anchor rod as the main means of support. Because bolt shot concrete support 
capable of forming a tight bond of flexible thin retractable supporting structure. It allows a certain degree of coordination surrounding rock deformation of supporting structure to withstand without causing excessive pressure.
Cross tunnel construction include: advance support, excavation, grill installation, after initial support backfill grouting construction. Formations and various supporting structure parameters in the following table:

TABLE I. THE PARAMETERS OF CALCULATION

\begin{tabular}{cccccc}
\hline Project & $\begin{array}{c}\text { Bulk density } \\
\gamma\left(\mathrm{kN} / \mathrm{m}^{3}\right)\end{array}$ & $\begin{array}{c}\text { Elastic modulus } \\
\mathrm{E}(\mathrm{MPa})\end{array}$ & $\begin{array}{c}\text { Cohesive } \\
\text { force } \mathrm{C}(\mathrm{kPa})\end{array}$ & $\begin{array}{c}\text { Internalfriction } \\
\text { angle } \varphi\left({ }^{0}\right)\end{array}$ & $\begin{array}{c}\text { Poisson } \\
\text { ratio } \mu\end{array}$ \\
\hline Plain fill & 17 & 50 & 10 & 8 & 0.35 \\
Pebble & 22 & 200 & 5 & 30 & 0.3 \\
Full weathered & 20 & 120 & 30 & 16 & 0.33 \\
calcareous slate & 25 & 30000 & & 0.2 \\
Shotcrete & 78 & 2000000 & & 0.3 \\
Bolt & & & & & \\
\hline
\end{tabular}

Theoretical analysis shows that the circular tunnel excavated in infinite domain of homogeneous and elastic is less than $1 \%$ when it's 5 times outside the scope of hole diameter is less than $5 \%$ when it's 3 times outside the scope of hole diameter because of the changes in stress and displacement of surrounding rock due to load release. considering the needs of engineering, the finite element

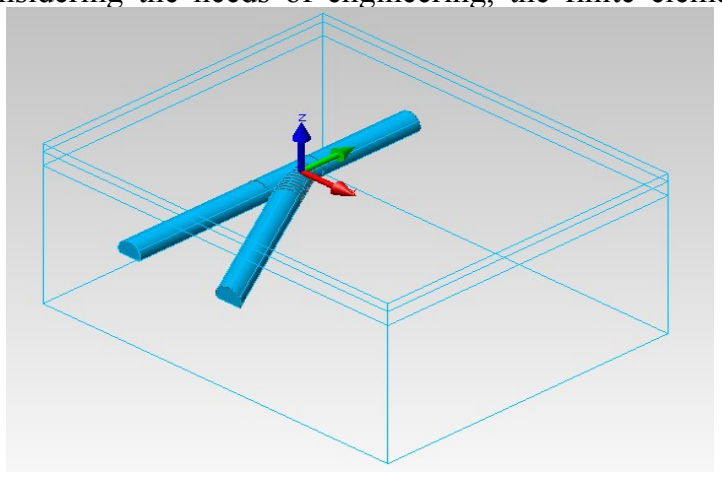

discrete error and calculation error, the general selection calculation along the hole diameter in all directions are not less than 3 5 times hole diameter. The whole model is divided into three layers, the thickness of each layer are respectively $2 \mathrm{~m}, 3.5 \mathrm{~m}, 34.5 \mathrm{~m}$. The selected model: length $130 \mathrm{~m}$, width $60 \mathrm{~m}$, high $40 \mathrm{~m}$. The crossing tunnel and the whole model as shown:

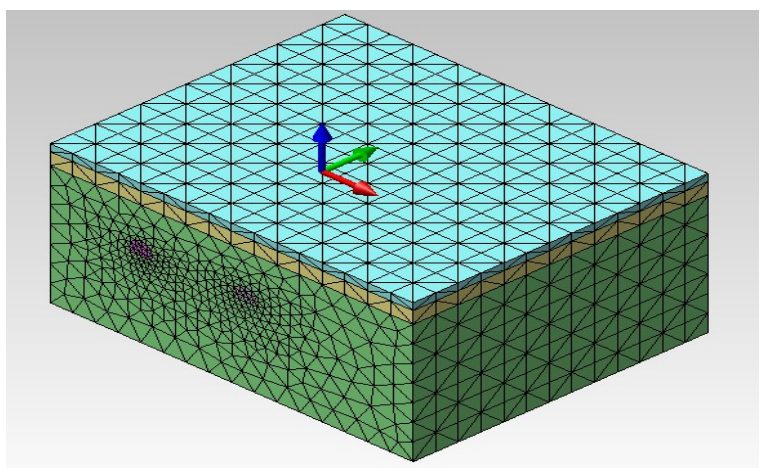

Figure 3. The Schematic Model of Calculation

\section{RESUlTS ANALYSIS}

Different Crossing Angle Settlement Analysis. The main tunnel and crossing tunnels before and after excavation displacement contours are shown as follows:

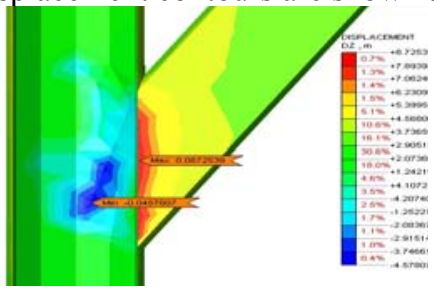

After the $30^{\circ}$ main tunnel excavation completed

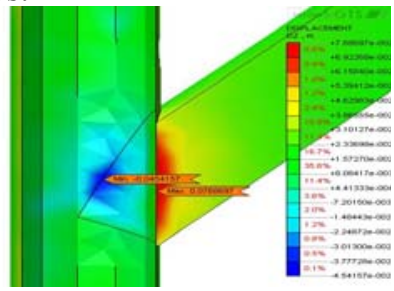

After the $45^{\circ}$ main tunnel excavation completed

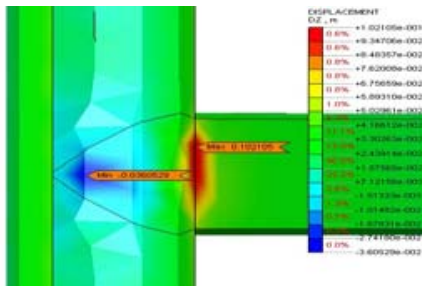

After the $90^{\circ}$ main tunnel excavation completed 


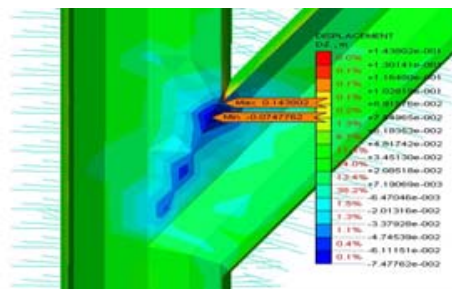

After the $30^{\circ}$ crossing tunnel excavation completed

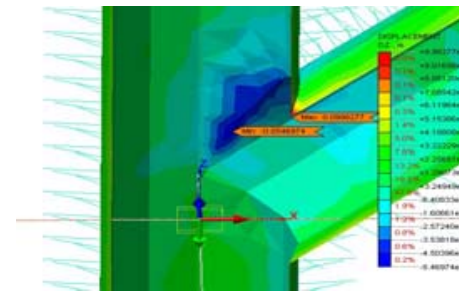

After the $45^{\circ}$ crossing tunnel excavation completed

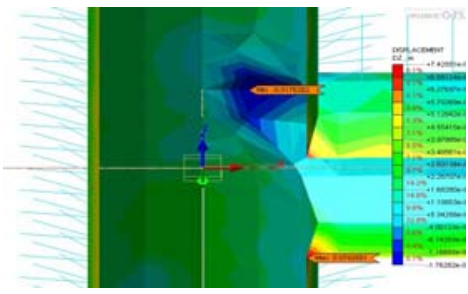

After the $90^{\circ}$ crossing tunnel excavation completed

Figure 4. The completion settlement comparison of different bifurcation angle of tunnel excavation

After the main tunnel excavation completed and before crossing tunnel excavated, sedimentation vault and floor uplift occurs at the intersection. $30^{\circ}$ vault settlement value is $-45.78 \mathrm{~mm}$. Surface uplift is $87.25 \mathrm{~mm}$. $45^{\circ}$ vault settlement value is $-35.54 \mathrm{~mm}$. Surface uplift is $56.87 \mathrm{~mm}$. Dome $90^{\circ}$ settlement value is $-36.05 \mathrm{~mm}$. Surface uplift is $61.10 \mathrm{~mm}$. Visible, $45^{\circ}$ excavation vault settlement value is minimum and the settlement value of the dome $30^{\circ}$ excavation has produced the greatest. The value of surface uplift generated by $90^{\circ}$ excavation is the largest and $45^{\circ}$ excavation surface uplift value is the minimum.

After cross tunnel excavation completed, $30^{\circ}$ excavation vault settlement value of the maximum reach

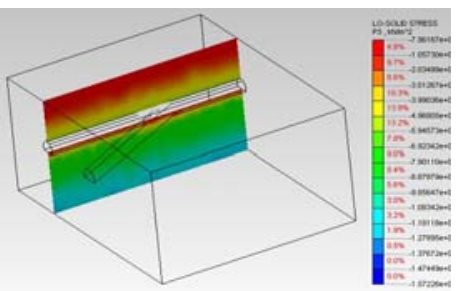

The $30^{\circ}$ tunnel maximum principal stress

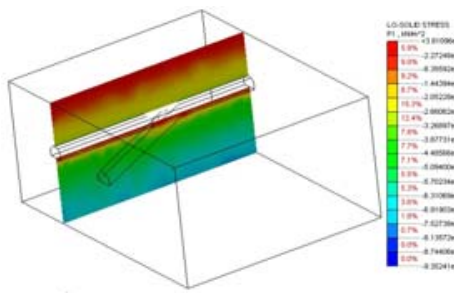

The $30^{\circ}$ tunnel minimum principal stress

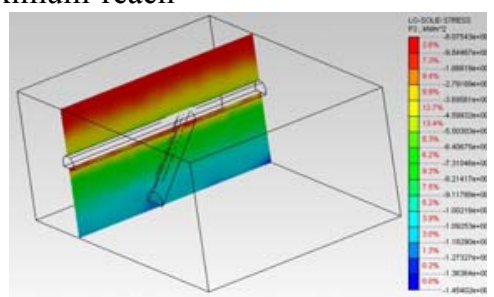

The $45^{\circ}$ tunnel maximum principal stress

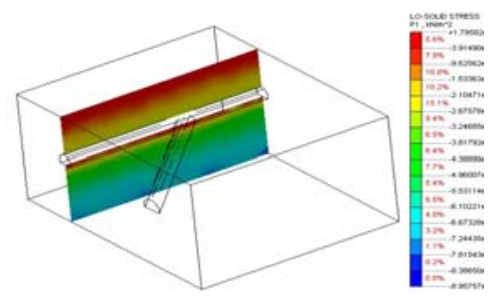

The $45^{\circ}$ tunnel minimum principal stress
$-74.77 \mathrm{~mm}$.Surface uplift is $143.8 \mathrm{~mm} .45^{\circ}$ excavation dome maximum settlement value is $-54.69 \mathrm{~mm}$. Surface uplift is $68.82 \mathrm{~mm} .90^{\circ}$ state excavation, vault settlement value up to $-67.62 \mathrm{~mm}$. Surface uplift is $74.25 \mathrm{~mm}$. According to above numerical simulation results, the maximum settlement value of the dome all occurred in the intersection of the tunnel. During the excavation of the tunnel along with ground uplift, its maximum value occurred in the bottom of the main tunnel and crossing tunnel.

Different Crossing Angle Principal Stress Analysis. Stress cloud chart is shown as follows: 


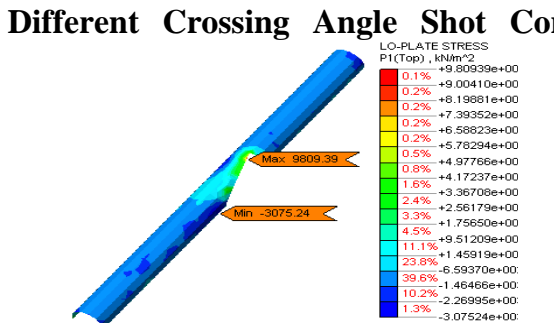

After the $30^{\circ}$ main tunnel excavation completed

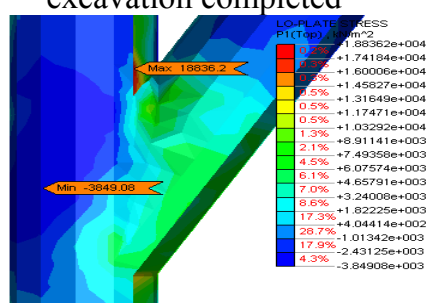

After the $30^{\circ}$ crossing tunnel excavation completed

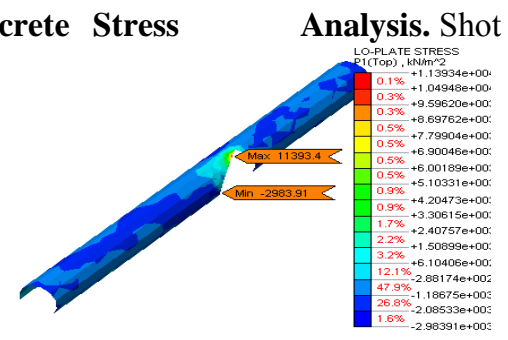

After the $45^{\circ}$ main tunnel excavation completed

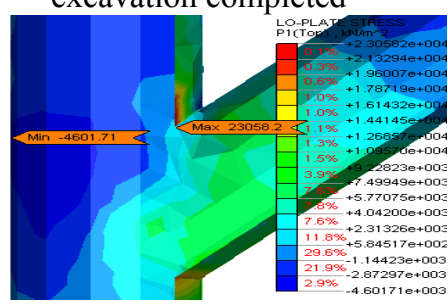

After the $45^{\circ}$ crossing tunnel excavation completed

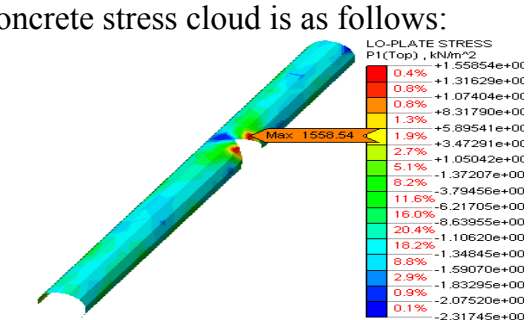

After the $90^{\circ}$ main tunnel excavation completed

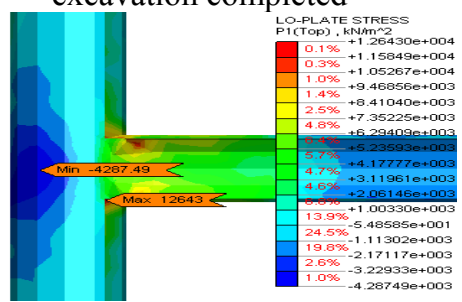

After the $90^{\circ}$ crossing tunnel excavation completed

Figure 6. The different bifurcation point of shot concrete stress analysis

Respectively with $30^{\circ}, 45^{\circ}$ and $90^{\circ}$ excavation, the maximum principal stress in the early stages of the tunnel support occurred in the main tunnel vault which is $12.8 \mathrm{Mpa}, 9.4 \mathrm{Mpa}, 11.6 \mathrm{Mpa}$. Maximum compressive stress occurred in the arch foot which is $3.2 \mathrm{Mpa}, 2.1 \mathrm{MPa}$, 2.3 MPa. After the crossing tunnel excavation completed, the maximum principal stress in the early stages of the tunnel support occurred in the arch foot which is $18.8 \mathrm{Mpa}, 10.2 \mathrm{Mpa}, 12.6 \mathrm{Mpa}$, The maximum compressive stress appeared in the arch foot of the other side which is
3.8MPa, 2.6MPa, 4.3Mpa. According to the numerical simulation results, with $30^{\circ}$ and $45^{\circ}$ excavation, the maximum principal stress appeared in the same position and direction. If it chooses $90^{\circ}$ excavation, the maximum principal stress at the dome compared to the previous two much is larger. So the second excavation scheme is reasonable.

Different Crossing Angle Bolt Stress Analysis. Different cross Angle, the main tunnel and cross tunnel anchor stress are shown in table 2 below:

TABLE II. BOLT STRESS VARIATION

\begin{tabular}{ccccc}
\hline $\begin{array}{c}\text { Cross } \\
\text { Angle }\end{array}$ & \multicolumn{2}{c}{ main tunnel excavation(MPa) } & \multicolumn{2}{c}{ Cross tunnel excavation(MPa) } \\
\hline \multirow{2}{*}{$30^{\circ}$} & maximum tensile stress & $4.75 \mathrm{E}+05$ & maximum tensile stress & $8.76 \mathrm{E}+05$ \\
& maximum compressive stress & $-3.16 \mathrm{E}+05$ & maximum compressive stress & $-8.64 \mathrm{E}+05$ \\
$45^{\circ}$ & maximum tensile stress & $3.96 \mathrm{E}+05$ & maximum tensile stress & $7.81 \mathrm{E}+05$ \\
& maximum compressive stress & $-2.15 \mathrm{E}+05$ & maximum compressive stress & $-5.83 \mathrm{E}+05$ \\
$90^{\circ}$ & maximum tensile stress & $3.76 \mathrm{E}+05$ & maximum tensile stress & $4.69 \mathrm{E}+05$ \\
& maximum compressive stress & $-2.20 \mathrm{E}+05$ & maximum compressive stress & $-6.26 \mathrm{E}+05$ \\
\hline
\end{tabular}

As can be seen from the above table data, with $30^{\circ}$ excavation, bolt tensile stress and compressive stress is the biggest. On the contrary, with $45^{\circ}$ excavation, it is the minimum. The construction of crossing tunnel has little disturbance on the formations. The stress of formation can be released in a certain degree. So the degree of bolt stress concentration is smaller Compared with the other programs. It has increased the stability of the tunnel supporting structure and ensured the safety of construction workers. In terms of the anchor rod stress, the second solution is more reasonable.

\section{V.CONCLUSIONS}

(1) With the main tunnel excavation completed, the initial stress field has been destroyed and the surrounding rock and supporting structure formed the secondary stress field. With the intersecting tunnel excavation completed, previous secondary stress field has been disturbed and finally formed the third stress field. Therefore the construction of crossing tunnels is the biggest risk source during the construction of intersecting tunnel. It needs to pay close attention to the situation of surrounding rock deformation and support timely to avoid the dangerous. 
(2) This paper uses MIDAS/GTS software for numerical simulation of tunnel construction process. It obtains that the supporting structure stress and deformation of surrounding rock of the main tunnel and cross tunnel under different excavation Angle. Excavated by $30^{\circ}$, at the intersection of two tunnels adjacent, surrounding rock stability has been greatest impact on, especially in the acute need to enhance support. Excavated by $45^{\circ}$, because of the soil thickening in the acute angle, the degree of stress concentration is reduced and bolt stress is smaller. In the same state supporting structure, the overall stability of the rock has been improved significantly and excavated by $90^{\circ}$, the value of vault settlement and the stress is larger.

(3) Excavated by $45^{\circ}$, it proves the rationality in the process of tunnel excavation at the aspects of the deformation of surrounding rock and supporting structure stress. Considering went in and out of the excavator, forklift in between two tunnels easily and the laying track, finally engineers select the second solution.

\section{ACKNOWLEDGEMENTS}

This thesis is successfully completed under the guidance of Professor Li Jinkui and the support of his fund project. Fund project: the national natural science fund project "the shell crushed surrounding rock of deep roadway anchor spray support mechanism research" (50704007).

\section{CORRESPONDING AUTHOR}

Name: Xianke Wei. Email:18617561784@163.com. Mobile phone: 18617561784.

\section{REFERENCES}

[1] Wang Mengshu .21 century's big tunnel and underground space development [J]. The Western Exploration Engineering, 2000, (1): 7-8 (In Chinese).

[2] Peng Bo. Excavation method and mechanical behavior of large-span tunnel intersection research: (a master's degree thesis). Chongqing: Chongqing Jiaotong University, 2012(In Chinese).

[3] T. Asano, M. Ishihara, Y. Kiyota, H. Kurosawa, S. Ebisu. An observational excavation control method for adjacent mountain tunnels. Tunnelling and Underground Space Technology. 2003, 18(2-3): 291-301.

[4] Li Xuangao. The method of Baziling crossing tunnel excavation method $[\mathrm{J}]$ Highway and Transportation Technology, 2006, (4): 136-140 (In Chinese).

[5] Liu Jinpeng. The related mechanic characteristics research of complex cross tunnel excavation: (a master's degree thesis). Chongqing: Chongqing University, 2008 (In Chinese).

[6] Li Qiang, Ceng Deshun. Shield construction of three-dimensional finite element analysis of vertical cross tunnel deformation [J]. Rock and Soil Mechanics, 2001, 22 (3): 334-338 (In Chinese).

[7] Liu Guangyao. Underground interchanges tunnel on the lower main tunnel construction scheme optimization research: (a master's degree thesis). Beijing: Beijing Jiaotong University, 2008(In Chinese).

[8] Zhang Xianxin. Deep cross tunnel excavation deformation behavior and the lining stress research [D]. Chongqing: Chongqing University, 2007 (In Chinese). 